\title{
Balancing ecosystem services with energy and food security - Assessing trade-offs from reservoir operation and irrigation investments in Kenya's Tana Basin
}

\author{
A. P. Hurford ${ }^{1,3}$ and J. J. Harou ${ }^{2,3}$ \\ ${ }^{1}$ HR Wallingford, Water Management Group, Wallingford, UK \\ ${ }^{2}$ The University of Manchester, School of Mechanical, Aerospace and Civil Engineering, Manchester, UK \\ ${ }^{3}$ University College London, Department of Civil, Environmental and Geomatic Engineering, London, UK
}

Correspondence to: J. J. Harou (julien.harou@manchester.ac.uk)

Received: 10 January 2014 - Published in Hydrol. Earth Syst. Sci. Discuss.: 30 January 2014

Revised: - - Accepted: 3 June 2014 - Published: 28 August 2014

\begin{abstract}
Competition for water between key economic sectors and the environment means agreeing allocations is challenging. Managing releases from the three major dams in Kenya's Tana River basin with its 4.4 million inhabitants, $567 \mathrm{MW}$ of installed hydropower capacity, 33000 ha of irrigation and ecologically important wetlands and forests is a pertinent example. This research seeks firstly to identify and help decision-makers visualise reservoir management strategies which result in the best possible (Pareto-optimal) allocation of benefits between sectors. Secondly, it seeks to show how trade-offs between achievable benefits shift with the implementation of proposed new rice, cotton and biofuel irrigation projects. To approximate the Pareto-optimal trade-offs we link a water resources management simulation model to a multi-criteria search algorithm. The decisions or "levers" of the management problem are volume-dependent release rules for the three major dams and extent of investment in new irrigation schemes. These decisions are optimised for eight objectives covering the provision of water supply and irrigation, energy generation and maintenance of ecosystem services. Trade-off plots allow decision-makers to assess multi-reservoir rule-sets and irrigation investment options by visualising their impacts on different beneficiaries. Results quantify how economic gains from proposed irrigation schemes trade-off against the disturbance of ecosystems and local livelihoods that depend on them. Full implementation of the proposed schemes is shown to come at a high environmental and social cost. The clarity and comprehensiveness of "best-case" trade-off analysis is a useful vantage
\end{abstract}

point from which to tackle the interdependence and complexity of "water-energy-food nexus" resource security issues.

\section{Introduction}

Dams necessarily interrupt the natural flow regime of rivers to produce their economic gains, causing environmental and potentially social disruption in the inundation and downstream areas (WCD, 2000; Renofalt et al., 2010; McCully, 2001). Traditionally, economic approaches are used to suggest efficient water management policies and plans (Wilson and Carpenter, 1999; Birol et al., 2006; Winpenny, 1993; Harou et al. 2009), but concerns have been raised regarding the ability of economics alone to assign value to nonmarket ecosystem goods and services or ensure their sustainability (Sagoff, 2011, 2008; Steele, 2009; Paton and Bryant, 2012; Abson and Termansen, 2011). In this paper economic and other objectives are evaluated and optimised to suggest how to operate and develop a water resource system. The trade-offs implied by the most promising management and investment decisions are presented so that stakeholders can holistically assess proposed system changes.

Many of the world's rural poor rely on ecosystem services provided by environmental resources. Their vulnerability increases and prospects for economic development reduce with the degradation of these resources (Malley et al., 2007; Juana et al., 2012; McCully, 2001). Water and poverty are linked (GWP, 2003); increases in access to irrigation, 
for example, can improve the circumstances of economically marginalised groups (Lipton and Litchfield, 2003). Storing water for distribution via built infrastructure increases access for those served but may reduce access for users downstream of the storage. "Re-operating" existing dams can increase water available to the rural poor and maintain or improve their ecosystem services at little or no cost to other stakeholders (Richter and Thomas, 2007; Watts et al., 2010; Konrad et al., 2012).

Integrated Water Resources Management (IWRM) (GWP, 2000 ) is the ideal approach for addressing complex interactions between water resource uses, incorporating social, economic and ecological goals. Merrey et al. (2005) propose that IWRM could better support rural livelihoods by taking a broader perspective - i.e., developing interdisciplinary models which integrate physical and social variables. In some regions there is a distinct water-energy-food security "nexus", implying these components must be managed as a system rather than in isolation (Granit et al., 2012). Independent attempts to achieve water security (Grey and Sadoff, 2007), energy security (Yergin, 2006) or food security (Godfray et al., 2010) will cause difficulties where these systems are interlinked, as progress towards one may stifle the others. Achieving "security" in these sectors requires understanding the trade-offs and synergies between them.

At the limits of a water resource system's utilisation, further gains of one benefit can only result from sacrifice of another. Quantified relationships between these gains and sacrifices are known as Pareto-optimal trade-offs (Cohon, 1978). They can be represented by curves (2-D) or surfaces (3-D) - both accepted tools of water management (Loucks et al., 2005). Understanding the form of trade-offs between four or more objectives (regarded as "many" objectives (Fleming et al., 2005)) can alter decision-makers' preferences and avoid the selection of "extreme" management policies which can result from considering smaller numbers of objectives (i.e. ignoring real system complexity) (Kollat et al., 2011). Opportunities can be revealed to achieve win-wins, where all parties benefit, or large gains for little or no sacrifice (Hurford et al., 2014).

Where classical multi-objective optimisation (Cohon, 1978; Yeh, 1985) struggles to define trade-off relationships with complex forms or between more than 2 objectives (Shukla et al., 2005), the most advanced many objective evolutionary optimisation algorithms (MOEAs) can simultaneously and reliably identify approximately Paretooptimal trade-offs between up to 10 objectives (Reed et al., 2013). Classical optimisation requires a priori preferences or weights to be declared regarding the different objectives so that multiple runs must be carried out with varying weights to define a trade-off curve; this is only practical for a small number of objectives. After a single run, MOEAs allow decision-makers to assess a posteriori the relative gains and sacrifices associated with a certain decision or set of decisions before selecting a balance between them
(Coello et al., 2007). MOEAs are coupled to external simulators representing complex non-linear systems, such as those already used by stakeholders to plan their own system. They generate discrete solutions which approximate the continuous Pareto-optimal curve or surface. Non-commensurate (e.g. non-monetary) objectives can be considered, meaning stakeholder-specific performance metrics can be developed without direct reference to monetary value and optimised alongside traditional economic objectives.

Several authors (e.g. Kasprzyk et al., 2009; Kollat and Reed, 2007) have demonstrated the use of trade-off plots to analyse solutions revealed by MOEA optimisation of water resources problems. Non-optimised information can be added to enhance understanding of the optimised policy implications for different stakeholders. Large data sets (thousands of points) can be analysed in a time-efficient manner facilitating more informed decision-making (Kollat and Reed, 2007; Lotov, 2007)

This paper contributes a many-objective visual trade-off analysis for the multi-reservoir hydropower system known as the Seven Forks project on the Tana River in Kenya. Volumedependent reservoir release curves are optimised for eight objectives covering municipal water provision, ecosystem services, and revenues from hydropower and irrigated agriculture. The same approach was first applied with different objective functions to a water, energy and food security problem and re-operation of dams in Brazil's Jaguaribe Basin by Hurford et al. (2014). The novel contribution of this paper lies in investigating the impacts on Pareto-approximate tradeoffs of different irrigation investment decisions alongside reservoir re-operation. The approach could augment conventional economic cost-benefit analysis for informing investment decisions, which often involve multiple stakeholders. Considering many objectives helps consider wider aims such as equity and sustainability of future plans. Visualisation of the trade-offs between many objectives facilitates a more intuitive understanding of the often complex cost-benefit (i.e. sacrifice-gain) relationships between them. The case study is outlined in the next section, followed by a description of the methodology before results are presented and discussed, then conclusions are drawn.

\section{Case study}

The Tana is Kenya's longest river and most significant hydropower resource (Fig. 1). The river experiences flood peaks in May and November resulting from the long and short rain seasons respectively.

Currently the five hydropower plants of the Seven Forks project in the Tana Basin provide around $70 \%$ of Kenya's electricity. Three plants are associated with storage dams - Masinga, Kiamburu and Kiambere. The other two (Gitaru and Kindaruma) are run-of-river plants with pondages upstream of their dams. The Masinga and 


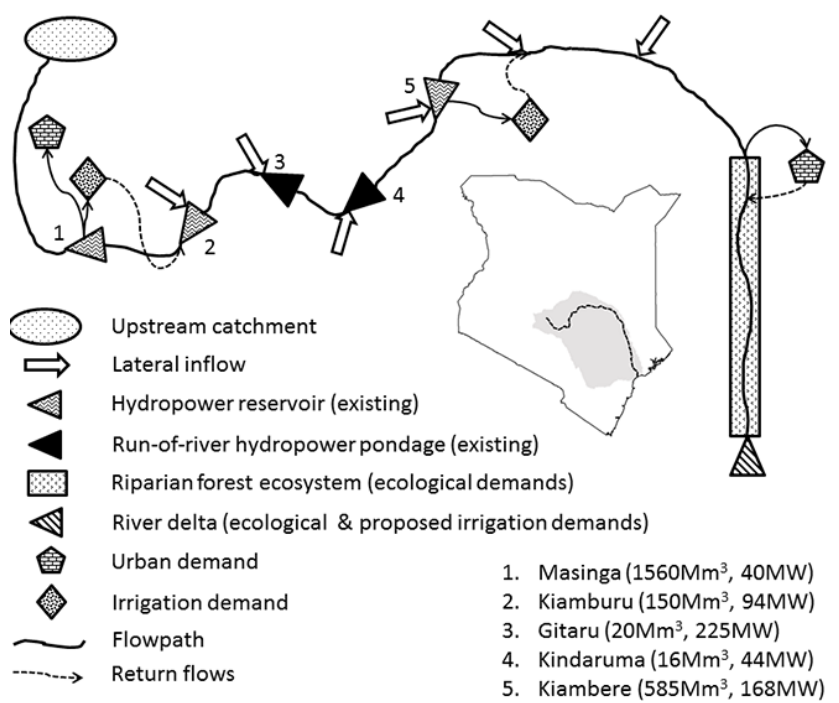

Figure 1. Tana River basin schematic. Inset map shows the location of the river and catchment within Kenya.

Kiambere reservoirs also provide water for irrigation and municipal demands. The dams have disrupted the flow regime of the river by augmenting low flows, reducing peak flows and reducing the number of days riparian land is flooded (Maingi and Marsh, 2002). Richter et al. (1996) discuss the importance of hydrological factors in maintaining ecological function.

The Tana River delta was recently classified as a protected wetland (Ramsar, 2012), requiring consideration of the sustainability of management practices in terms of both the local ecosystems and livelihoods. The physical, chemical and biological characteristics of this wetland have resulted from the historic extent, timing duration and frequency of flood events (Mitsch and Gosselink, 2000). Maintenance of these characteristics amounts to a major demand for water, in competition with other demands. In the dry season, the delta provides high-quality grazing land for large numbers of pastoralists, constituting a high value ecosystem service (Davies, 2007).

Protected high-biodiversity riverine forests upstream of the delta are home to endemic and endangered species of primates (Karere et al., 2004) and the health of their ecosystems relies on regular floods (Hughes, 1990) and low flows (Kinnaird, 1992). Documented flow changes will have a negative impact on these forests (Maingi and Marsh, 2002). The natural variability of flows historically replenished nutrients on riparian agricultural lands and in the delta. Sediments deposited lead to beneficial morphological change. These ecosystem services are also under threat from the alteration of the flow regime (Emerton, 2005; Leauthaud et al., 2013).

Several large irrigation schemes are planned for the Tana Delta including 20000 ha of sugarcane, 16500 ha of cotton and 21600 ha of irrigated rice. If implemented, these schemes could threaten current social and ecological func- tions of the delta and potentially decrease its value as a tourism resource (Mireri et al., 2008).

\section{Methodology}

A multi-criteria search (optimisation) algorithm is linked to a water resource management simulator of the basin in order to define a set of discrete solutions approximating the Pareto-optimal set. The solutions cannot be mathematically proven to be Pareto-optimal, but the evolution of the solution set can be visually analysed for convergence on and diversification across the Pareto-approximate surface. To simplify the discussion we refer to the trade-offs from here on as Pareto-optimal. The approach is initially used to reveal tradeoffs for the current system (no new irrigation schemes). In a second case new irrigation water demands are introduced to investigate their impact on trade-offs. This demonstrates how adding irrigation investments impacts the trade-offs that map the social-economic-ecological and engineering performance of the system. Trade-off plots help to understand and communicate the trade-offs implied by different management decisions. This section first describes the features of the basin model before explaining how the search algorithm interacts with it and how trade-off plots help to understand results.

\subsection{Water resource management simulator}

The IRAS-2010 water resources management simulator (Matrosov et al., 2011) is used to model the Tana Basin water resources system. Model nodes represent storage reservoirs, run-of-river pondages, abstraction points, demands and flow monitoring locations. Links connect nodes to provide flow paths representing the main river channel, dam release gates and spillways, hydropower turbines, abstractions and return flows.

Initial reservoir/pondage storages are set at $50 \%$ of their maximum capacity as historical level data were not available. The upstream boundary condition is a 42-year historical (1934-1975) inflow time series from a point downstream of the dams. This represents pre-dam development conditions and is used as the basis for analysing variations from the natural flow regime. The flow series was disaggregated based on relative flow proportions in Kiptala (2008) into an upstream catchment inflow series and seven lateral inflow series. The downstream boundary at the delta does not account for tidal backwater effects restricting river flow. A monthly (30-day) time step is used; water entering the system passes through it within a single time step, making flow routing unnecessary.

In the current water demands case, public water supply and irrigation are abstracted from reservoirs, taking precedence over hydropower releases. This means the hydropower plant will receive no water until other demands are satisfied. It is necessary to prioritise demands in IRAS-2010 and this 
approach has little impact while storage is high, but best represents the likely results of political pressure under drought conditions. Current demands on the reservoirs for irrigation and municipal supplies are shown in Table A1; proposed additional demands are in Table A2.

Consistent with Kiptala (2008), return flows to the river are a constant $30 \%$ of irrigation abstractions, except for the proposed schemes in the delta. These are assumed to be returned to multiple minor channels flowing to the ocean and thus not included in flow measurements at the delta. It is assumed that no return flows to the Tana occur from the public water supply, as the major abstraction is for Nairobi which lies outside its basin.

The reservoirs and rivers in this semi-arid region evaporate roughly $2000 \mathrm{~mm}_{\text {year }}{ }^{-1}$. The monthly mean daily evaporation rate for Muguga was increased by $10 \%$ (according to maps and data supplied by Dagg et al. (1970)) for reservoir evaporation and by $43 \%$ for river channel evaporation in the lowlands.

\subsection{Optimisation approach}

The IRAS-2010 simulator is linked to a multi-criteria search (optimisation) algorithm (the epsilon dominance nondominated sorting genetic algorithm-II ( $\varepsilon$-NSGAII) (Kollat and Reed, 2006; Reed et al., 2013)). This combined approach identifies multi-reservoir release policies which achieve Pareto-optimal trade-offs between eight objectives. This section describes interactions between the search algorithm and the model then the optimisation formulation.

\subsubsection{Simulation-optimisation interactions}

The optimisation algorithm adjusts decision variables within the model to alter its behaviour and simulate the impacts of different reservoir operation and irrigation investment policies. Variables are selected at the beginning of each simulation and apply for its duration. Initial policies (sets of variables) are drawn randomly from defined decision variable ranges. Impacts are measured in terms of defined objectives for (benefits from) the system. Over thousands of simulation runs (100000 in this case, consistent with Kasprzyk et al., 2009), the algorithm iteratively attempts to increase benefits based on objective evaluations of previously simulated policies. The Pareto-optimal "frontier" is revealed as the algorithm finds and explores the performance limits of the system. Results comprise a set of individually unique trade-off solutions and the policies (releases and investments) required to achieve them.

\subsubsection{Decision variables}

The decision variables of the optimisation are the release rules of the three managed hydropower reservoirs (Masinga, Kiambere and Kiamburu) and (for the 2nd case only), the proportion of each proposed irrigation scheme which is

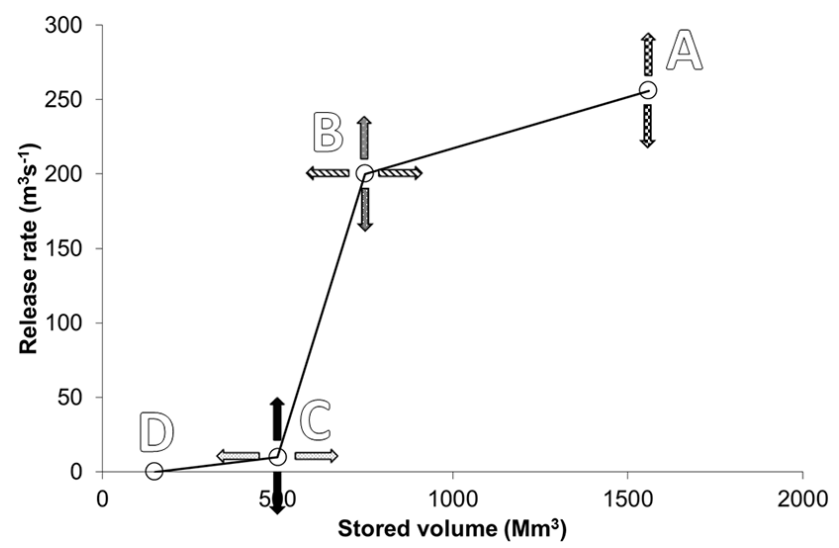

Figure 2. Reservoir release rule (hedging) curves as represented by the IRAS-2010 model. Each patterned pair of opposing arrows represents an optimisation decision variable. Point $\mathrm{D}$ is the dead storage of the reservoir. Point A represents the controlled release when the reservoir is full. $\mathrm{B}$ and $\mathrm{C}$ points can be varied in two dimensions for hedging. In total, five decision variables define each reservoir's release rule.

implemented. The other two hydropower stations (Gitaru and Kindaruma) are run-of-river and receive flows limited only by available storage and their maximum turbine flow capacities.

IRAS-2010 has a feature for implementing the standard operating policy (SOP, Maass et al., 1962) for reservoirs. We used this feature to create hedging rules similar to those used by Shih and Revelle (1994) but using only present storage to decide releases. Release rule decision variables comprise three plotting coordinates (i.e. five values), defining a continuous piecewise linear curve which relates stored volume to release rate (Fig. 2). Reservoir-specific curves dictate the release rate at each simulation time step. In total, 15 decision variables control releases. The releases' range is 0 $400 \mathrm{~m}^{3} \mathrm{~s}^{-1}$ consistent with Kiptala (2008). The storage variables' range is from dead storage to maximum storage specific to each reservoir. A single curve is applied throughout the year to represent a conservative approach - release rates are dictated only by current storage volume, unaffected by anticipation of a forthcoming rainy season. Information on whether or how forecasts are currently used in Tana reservoir operation was not available in this study. Although irrigation and municipal abstractions are directly from the reservoir and prioritised over hydropower releases, they are limited by the release rule.

There are four proposed new irrigation schemes in the delta (Table A2). The proportion of each scheme included in an individual simulation is dictated by an integer decision variable of range $0-100 \%$. In the current demands case, these variables are all fixed at $0 \%$. 


\subsubsection{Objectives}

The impacts of each set of decision variables (operation and investment policy) are evaluated with respect to eight objectives, each of which is either maximised or minimised by the search algorithm. Objectives are detailed in Appendix B and outlined as follows.

Supplies to Nairobi and Kitui are represented by an abstraction from Masinga reservoir and an abstraction from the river downstream of the dams serves small local urban centres. Municipal supply deficit is minimised dependent on reservoir release rules and stored water volume.

Hydropower revenue is maximised dependent on hydraulic head levels in the associated reservoir or pondage, flow rate through the turbines and timing of releases as bulk energy prices vary though the year.

Failure to meet electrical base load or peak demands causes economic losses and can hamper development. A firm energy objective is to maximise the electrical output $(\mathrm{GWh})$ at $90 \%$ reliability over the course of the simulation. Peak daily power demands are not analysed in this study as they cannot be captured by the monthly model time step. Monthly electrical demand variations are captured by fixed monthly bulk energy prices representing fluctuations according to supply and demand.

Existing irrigation provision in the basin does not place a strain on water resources, as the volume required (Table A1) is small relative to storages and annual flows in the river (Kiptala, 2008). In re-operating the system however, crop revenues can vary as a result of policies causing irrigation deficits. Agricultural revenue is maximised dependent on minimising crop water deficits during growing seasons. In the proposed demands case it also depends on the selection of crop type, which dictates water requirements and yield response to deficit. A module was added to IRAS-2010 to evaluate crop-specific yields and reductions due to irrigation shortfall (Appendix C).

Following Connell's (1979) Intermediate Disturbance Hypothesis (IDH) we assume that river flow variability represented by the natural flow duration curve is most likely to support healthy native ecosystems. Following Gao et al.'s (2009) eco-deficit approach, a flow alteration objective is used to minimise deviation of the regulated from the natural flow regime. Separate objectives are evaluated for deviation at the delta and the riverine forests as proposed demands are abstracted between them, causing an unequal impact.

Flood magnitude and timing are components of Richter et al.'s (1996) indicators of hydrological alteration relevant to ecological health. Flood peaks in the Tana Basin support ecological function and supply agricultural and grazing lands with nutrient-rich sediments and water. Two flood peak objectives are evaluated at the delta, as the most important provider of flood-related ecosystem services, to minimise the difference between the natural and modified flood peaks: one for each of the long and short flood seasons (April-June and November-December, respectively).

\subsubsection{Problem formulation}

Trade-offs are generated for the two cases which share a common problem formulation (Eq. 1). Objective functions included in the formulation are detailed in Appendix B. In the current demands case there is no abstraction for proposed irrigation schemes between the locations where $f_{\text {flowFOR }}$ and $f_{\text {flowDEL }}$ are evaluated, so these objectives have similar values (evaporation causes reductions downstream). Optimisation algorithm parameters are consistent with Kasprzyk et al. (2009).

$$
\begin{aligned}
& F(x)=\left(f_{\text {mun }}, f_{\text {hydro }}, f_{\text {firm }}, f_{\text {agric }}, f_{\text {flowFOR }},\right. \\
& \left.\quad f_{\text {flowDEL }}, f_{\text {flood }}^{\text {long }}, f_{\text {flood }}^{\text {short }}\right) \\
& \forall x \in \Omega \\
& x=\left(X_{i}, \operatorname{Irrig}_{j}\right),
\end{aligned}
$$

where $i$ is a reservoir, $i \in\{$ Masinga, Kiamburu, Kiambere $\}$, $j$ is a proposed irrigation scheme in the delta, $j \in$ \{Rice(season1), Rice(season2), Cotton, Sugarcane\} $X_{i}$ represents a reservoir $i$ 's release rule, Irrig $_{j}$ represents the percentage of a proposed irrigation scheme $j$ which is implemented, and $\Omega$ represents the whole decision space.

\subsubsection{Visual analytics}

We develop trade-off plots built using interactive visual analytics (e.g. Kasprzyk et al., 2009; Kollat and Reed, 2007; Keim et al., 2008) to explore trade-offs between competing objectives and other relationships, adjusting the information displayed to highlight different features. Interactive trade-off visualisation provides a broad perspective on the multiple objective performances and decisions which produced them. Large solution sets can be analysed in plots with high information content facilitating more informed deliberation and decision-making (Kollat and Reed, 2007; Lotov, 2007). The figures below and the animations in the Supplement illustrate how trade-off visualisation helps balance water benefits by showing how different goals trade-off against each other. Any selected solution point from the trade-off curve/surface represents the performance achieved for all objectives by a specific set of decision variables (a "policy").

\section{Results}

This section relates the results of the two optimised cases, starting with the current demands case. The search (optimisation) process requires many simulation runs and is carried out using high-performance parallel computing, available on university clusters, or commercially using the cloud. The two cases presented here each completed 100000 function 

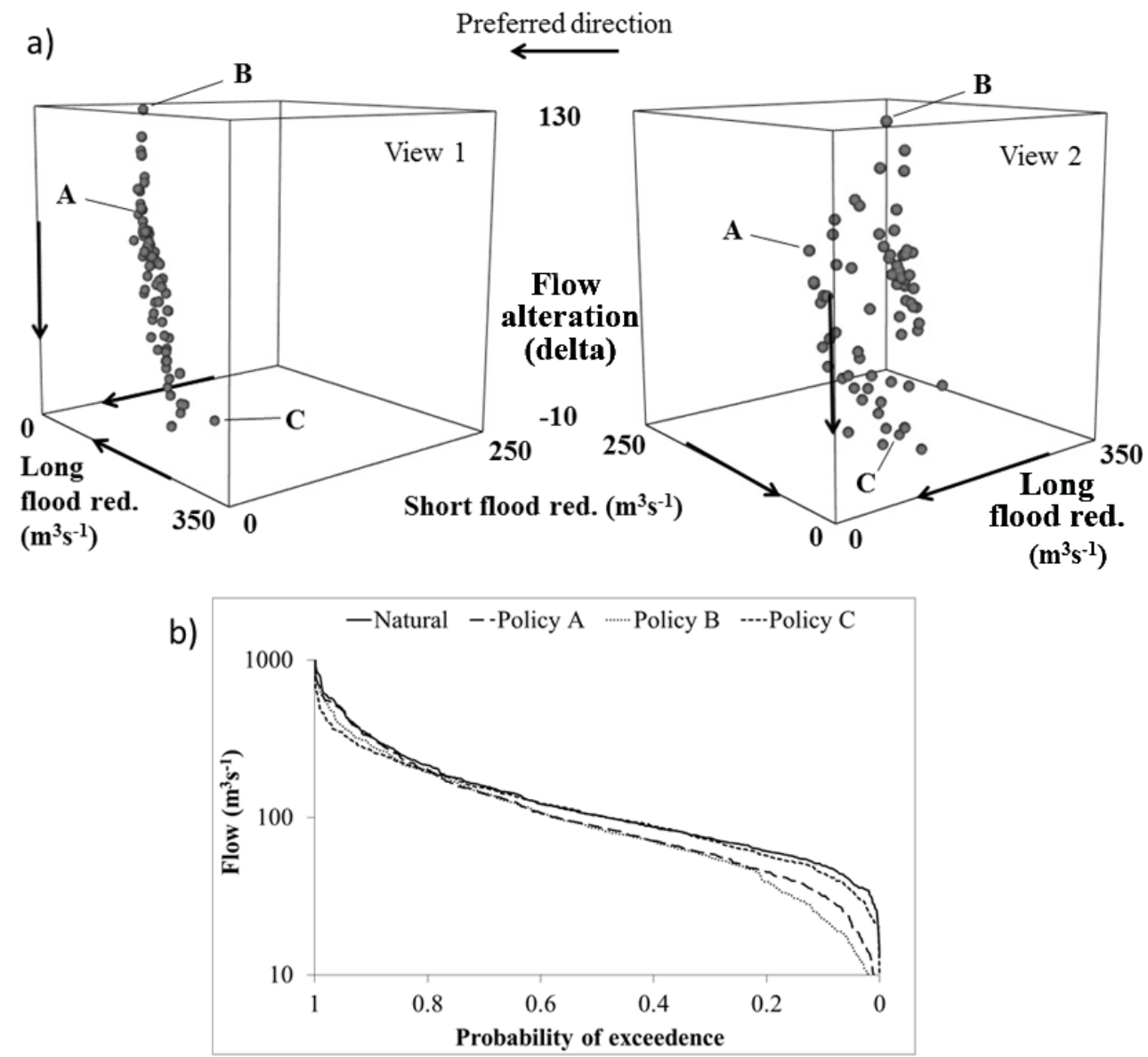

Figure 3. (a) Two views of the trade-off surface between flow-related objectives. Flow regime alteration decreases as flood peaks are reduced, allowing lower flows to be maintained closer to the natural regime. Three policies are highlighted and referred to in the text and subsequent figures. A 3-D animation of this plot is available in online supplementary material. (b) Comparison of the flow duration curves resulting from policies A, B and C in (a). Policy $\mathrm{C}$ allows around $20 \%$ of highest flows to diverge from the natural curve to augment lower flows, maintaining them closer to the natural regime. Policy A achieves the reverse.

evaluations (42-year simulations) in $1.75 \mathrm{~h}$ using forty-eight $2 \mathrm{GHz}$ processors. Visual analysis of the search progress and a random seed analysis (e.g. Kollat et al., 2008) testing 50 iterations of the same optimisation process confirmed that 100000 evaluations were sufficient to approximate the Pareto-optimal set and only diversification of results would be gained by extending the search. If decision-makers focus on a relatively small area of the initial trade-off surface, an extended search could be undertaken to help diversify the options over that limited area.

\subsection{Current demands case}

This section steps through the construction of a sixdimensional trade-off surface. In the process we highlight the varying impacts on the system of selected policy solutions.

Support of ecological function and ecosystem services is investigated first from the perspective of the three flowrelated objectives. Trade-offs exist between reduction of the two annual flood peaks (Fig. 3a) because water which is released to increase one flood's magnitude is no longer available to increase the other. Flow regime alteration trades off against both flood peak objectives. Greater overall disturbance of the flow regime is required to support flood peaks closer to those naturally occurring. The volume of water released to maintain the highest $20 \%$ of flows can alternatively maintain the lowest $80 \%$ of flows (Fig. 3b). The tradeoff surface is non-linear, incorporating convexities and concavities with respect to the origin (perfect solution). Gainsacrifice gradients vary across the surface.

Firm energy production is added to the trade-off surface through sizing of the spheres. Larger spheres indicate higher firm energy levels. Hydropower revenue is represented by a colour range applied to the spheres (Fig. 4a).

In this and subsequent figures trade-off surfaces are simplified by controlling the resolution at which solutions are displayed. As this reduces the number of solutions shown, 

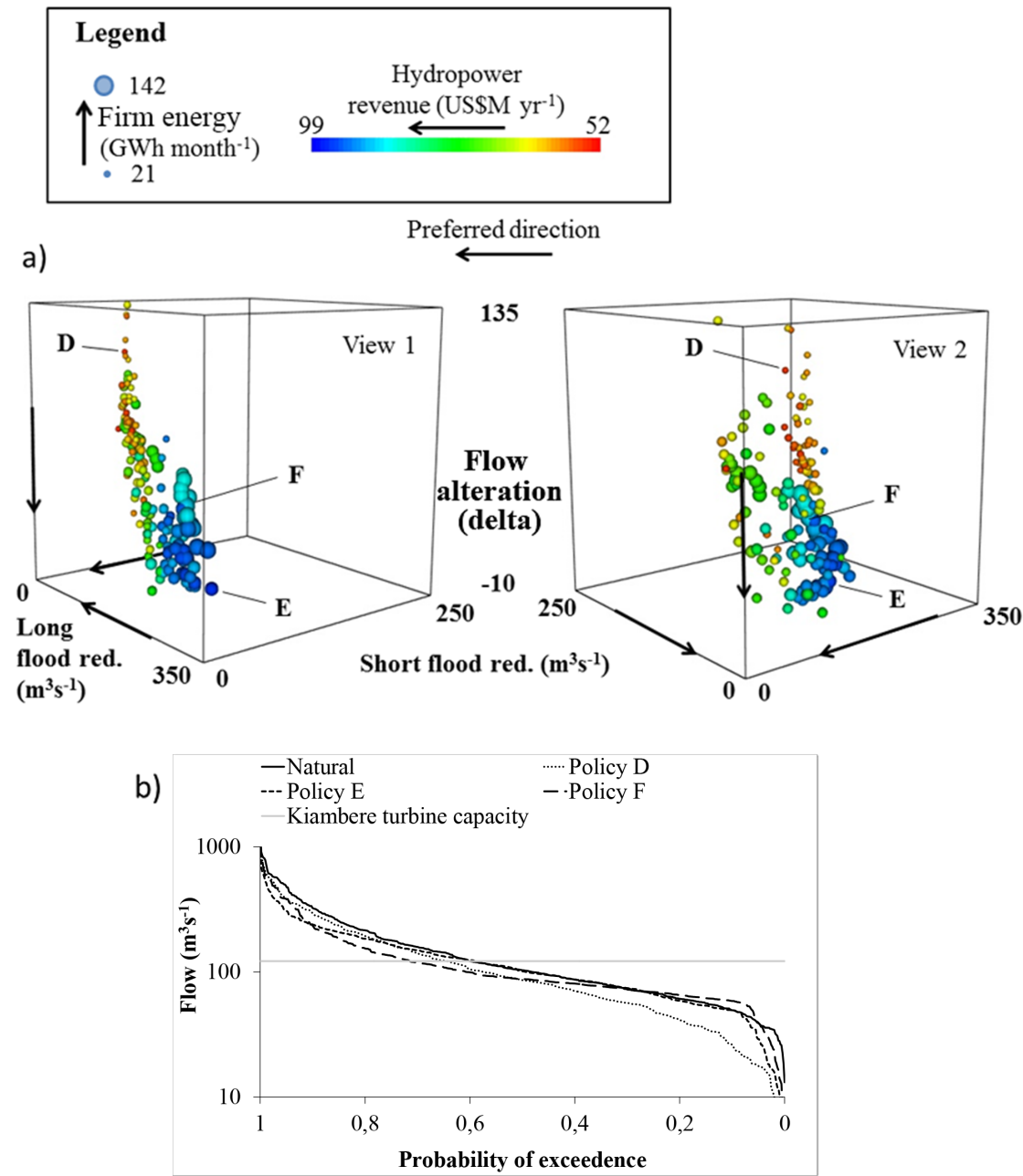

c)

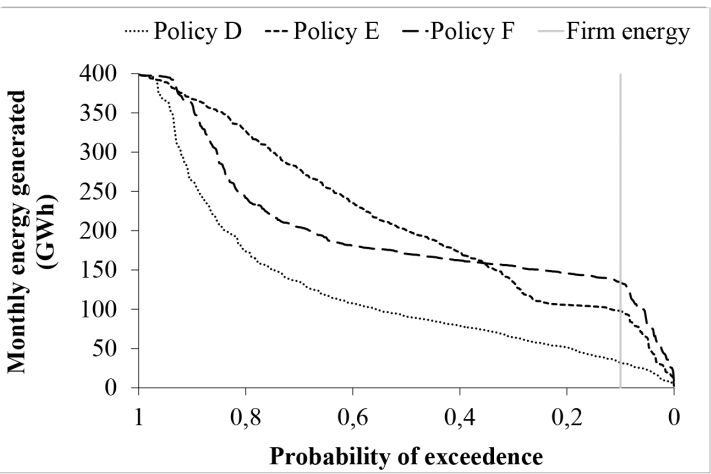

Figure 4. (a) The same trade-off surface as Fig. 3a with firm energy added using sphere size and hydropower revenue shown with colour. Larger spheres indicate higher firm energy; blue spheres mean high revenues. Three policies (D, E, F) illustrate trends across the surface. Moving from D to E, hydropower revenue increases as flood peaks are reduced but flow regime alteration becomes less pronounced. From $\mathrm{E}$ to $\mathrm{F}$ long flood peaks are increased as a result of higher storage levels, increasing uncontrolled releases, and flow regime alteration is increased to conserve water for firm energy generation. (b) Comparison of the natural flow duration curve with those resulting from the three selected policies of (a). Lower flows are increased by sacrificing higher flows as we move across the trade-off surface in (a) from Policy D to E. This results in $79 \%$ higher hydropower revenue. The Policy E curve departs from the natural curve at the turbine flow (i.e. productive) capacity of the Kiambere plant. Policy F brings around $10 \%$ more flows within the productive capacity at Kiambere than Policy E and increases low flows above the natural regime. (c) Energy generation implications of the three policies labelled in (a). Firm energy is the level of generation which can be provided with $90 \%$ reliability. Policy F best sustains energy generation to achieve firm energy $326 \%$ higher than Policy D and $37 \%$ higher than Policy E. 
decision-makers would be asked to choose a preferred region of the surface before all Pareto-optimal points are reintroduced for investigation of detailed solutions. As objectives (dimensions) are added to the surface, the number of solutions included in it increases. An objective's poorest performance can decline further as it is traded off against additional objectives. Maximum flow alteration is increased to 135 in Fig. 4a to accommodate the new surface.

Firm energy trades off against flood peak objectives as it increases when flood water is stored to secure generation during drier periods. It also trades off against the flow alteration objective as relatively constant flow provides higher firm energy than natural variability.

Between Policy D and E (Fig. 4a) there is a trend for increasing hydropower revenue as flow becomes more natural (as defined by the objective function) but flood peaks reduce. Exceptions to this trend result from the limited scope for upstream dam operations to increase revenue without impacting on the flow-related objective values controlled by Kiambere - the last hydraulic structure represented in the system model.

Flow alteration is decreased from Policy D to E by releasing water to maintain low flows rather than high flows (Fig. 4b). This increases the proportion of flows released through the turbines of the Kiambere hydropower plant because they do not exceed its flow capacity, thereby increasing revenue. The flow duration curve from Policy E departs from the natural curve at the turbine capacity of the Kiambere plant as additional flow beyond this magnitude generates no additional revenue.

Policy $\mathrm{F}$ brings around $10 \%$ more flow duration within the productive capacity of the Kiambere turbines than Policy E. In addition, some of the high flow volume made available is released to increase the lowest flows above the natural level (Fig. 4b). This more constant flow achieves higher firm energy generation (Fig. 4c).

Agricultural revenue is added to the trade-off surface by converting spheres to cones whose orientation indicates its magnitude (Fig. 5). Cones pointing down indicate low revenues; cones pointing up show high revenues. Maximum flow alteration is increased to 195 to accommodate the new surface.

High agricultural revenue depends on both reliable supply (storage) and release rates at the Masinga and Kiambere reservoirs. Storage levels alone are not a predictor of agricultural revenue, as without the operating rules allowing releases, crops cannot be irrigated. Agricultural revenue trades off against reduction of flood peaks and alteration of the flow regime for example, even though they increase storage levels. There is also a trade-off with hydropower revenue, which benefits from some storage but requires higher releases which impact on storage. The maximum mean annual revenue achieved by the optimisation represents no reduction from the maximum possible annual revenue (i.e. there are no irrigation deficits).

\subsection{Proposed demands case - implementing irrigation schemes in the delta}

Having identified the trade-offs in the system under current water demands, we now compare them with the Pareto set addressing the question: "what proportions of the proposed irrigation schemes should be implemented?". Figure 6 shows the trade-off surface combining both cases to illustrate how the surface changes following the introduction of potential irrigation investments. Maximum flow alteration is increased to 1072 and maximum agricultural revenue increased to USD 285 million.

Figure 7 shows the trade-offs between the same metrics as Fig. 5; this shows how ecological flow characteristics tradeoff with increased agricultural revenues. New irrigation can lead to a more altered regime.

In the current demands case, agricultural revenue could be increased without irrigation development in the delta by reducing the long flood peak magnitude. With the new delta irrigation schemes, the short flood peak is further reduced to provide further increases in agricultural revenue, even with increased long flood peaks. The sugarcane crop requires year-round irrigation and cotton is irrigated through the short flood season.

Whilst it is not possible to generate more hydropower than that obtained in the current demands case, it is possible to maintain generation levels while almost doubling agricultural revenues. To attain the highest agricultural revenues however, hydropower revenue must decrease. Potential to increase agricultural revenues must be traded-off against the associated impacts on hydropower revenue, flows, floods and associated ecosystem services.

Figure 8 relates the details of the delta irrigation schemes implemented in Fig. 7, showing the combinations of schemes which achieve different total agricultural revenues. The highest revenues can be gained either with or without cotton cultivation. A high proportion of the rice and sugar schemes must all be implemented to maximise revenue.

\subsection{How to select a balanced plan?}

Exploring trade-offs is insightful, but ultimately the proposed approach is designed to assist with decision-making. Next we demonstrate an approach that could help decisionmakers settle on a plan - in our case the combination of a set of reservoir operating rules and a portfolio of new irrigation schemes. This involves (a) filtering the Pareto-front so that only decision-maker-preferred solutions figure there, (b) identifying promising areas of the trade-off curve from which to choose example plans (individual trade-off solutions) to assess in more detail, and (c) for those example plans looking at performance metrics and decision variables. In this work we did not involve decision-makers; here we only describe a proposed approach. 
Legend
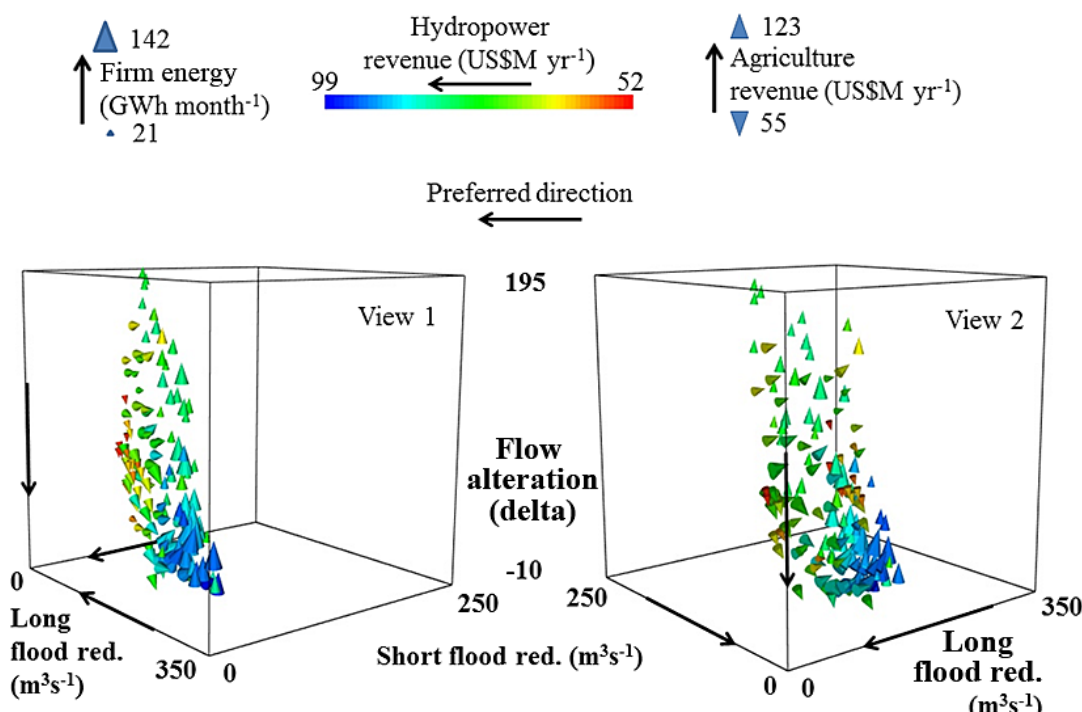

Figure 5. The same trade-off surface as Fig. 4a with cones replacing spheres. Their orientation shows agriculture revenue from lowest (pointing down) to highest (pointing up). Agriculture revenues trade-off against flood peak objectives and correlate with firm energy, except at the highest agricultural revenues, where there is a trade-off.

We begin by filtering the Pareto options to arrive at those of primary interest to decision-makers. For our case study we postulate that decision-makers will be most interested in solutions that ensure high reliability of municipal supply and therefore filter the trade-off surface to only allow policies which result in no municipal deficit (Fig. 9a). From this surface, following step (b) above, we select three promising policies to demonstrate how resulting benefits vary between them.

Finally, following step (c), we generate detailed plots and a table (Table 1) that show the performance of our example policies in detail. For example, Fig. 9b compares the natural and actual flow duration curves resulting from each policy. None of the selected policies are amongst the highest performers in terms of flow alteration, but they deviate from the natural regime in different ways. Policy $\mathrm{H}$ generates the most hydropower revenue by favouring release rates close to the turbine capacity of the Kiambere hydropower station. Policy G results in better flow alteration performance at low and high flows, resulting in high firm energy but lower hydropower revenues. Although around $20 \%$ of its highest flows are closer to natural than the others, Policy I results in the greatest alteration of the regime to increase agricultural revenue. The delta irrigation schemes are almost fully implemented (Table 1). Both policies which implement new irrigation schemes result in the delta receiving no water, except return flows from irrigation schemes, for $1-2 \%$ of the time.

Figure $9 \mathrm{c}$ illustrates the monthly trends in hydropower production for policies G-I. The highest revenue (Policy H) is achieved by generating more power when the bulk energy price is highest. There are 4 months where Policy G produces more energy than Policy $\mathrm{H}$, however.

\section{Discussion}

We have demonstrated an approach using a many-objective trade-off analysis to help make balanced water management and planning decisions in complex systems with multiple societal benefits. The framework is applied to Kenya's Tana River system with the goal of finding an appropriate set of operating rules for a multi-reservoir system and sizing new irrigation schemes. We report on the approach as a proof of concept as work with decision-makers there has not yet begun. The approach aims to allow decision-makers to visualise the precise trade-offs they face when choosing amongst a subset of "best" (Pareto-optimal) policies identified by a multi-criteria search algorithm. Analysing trade-offs visually fosters an intuitive understanding of the relationships between gains and sacrifices intrinsic to the system. The approach can be considered a multi-criteria form of costbenefit analysis (Chakravarty, 1987) where costs and benefits of the best interventions considering multiple metrics (monetary or not), and their gain-sacrifice relationships, are displayed simultaneously.

The decision-making framework involves two steps: (1) settling on a framing of the planning decision that is preferred by decision-makers, then (2) probing the trade-offs (Pareto-optimal policies) to identify a few alternatives to investigate in detail. 
Table 1. Objective values and irrigation scheme implementation percentages for selected operating policies from Fig. 12.

\begin{tabular}{llrrr}
\hline & & \multicolumn{3}{c}{ Operating policy } \\
\cline { 2 - 5 } Objective & Units & $\mathrm{H}$ & $\mathrm{I}$ & $\mathrm{J}$ \\
\hline Municipal deficit & Mm $^{3}$ year $^{-1}$ & 0.0 & 0.0 & 0.0 \\
Hydropower revenue & USD million year $^{-1}$ & 88.0 & 92.7 & 82.1 \\
Firm energy (90\%) & GWh month $^{-1}$ & 131.1 & 105.1 & 79.9 \\
Agricultural revenue & USD million year $^{-1}$ & 121.8 & 241.4 & 277.2 \\
Flow regime alteration (Forest) & - & 36.4 & 23.2 & 49.5 \\
Flow regime alteration (Delta) & - & 38.3 & 134.1 & 568.8 \\
Long flood peak reduction & $\mathrm{m}^{3} \mathrm{~s}^{-1}$ & 177.3 & 228.1 & 179.7 \\
Short flood peak reduction & $\mathrm{m}^{3} \mathrm{~s}^{-1}$ & 77.6 & 151.3 & 173.4 \\
\hline Delta irrigation implementation & & & & \\
Rice (season 1) & $\%$ & 0 & 86 & 100 \\
Rice (season 2) & $\%$ & 0 & 98 & 97 \\
Cotton & $\%$ & 0 & 69 & 31 \\
Sugarcane & $\%$ & 0 & 30 & 100 \\
\hline
\end{tabular}

\section{Legend}

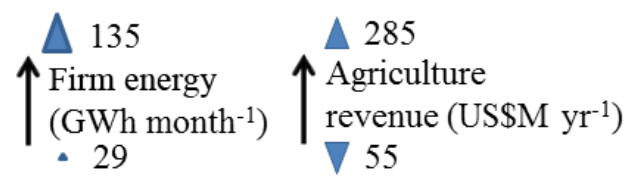

A Current case trade-offs

$\boldsymbol{\Delta}$ Proposed case trade-offs

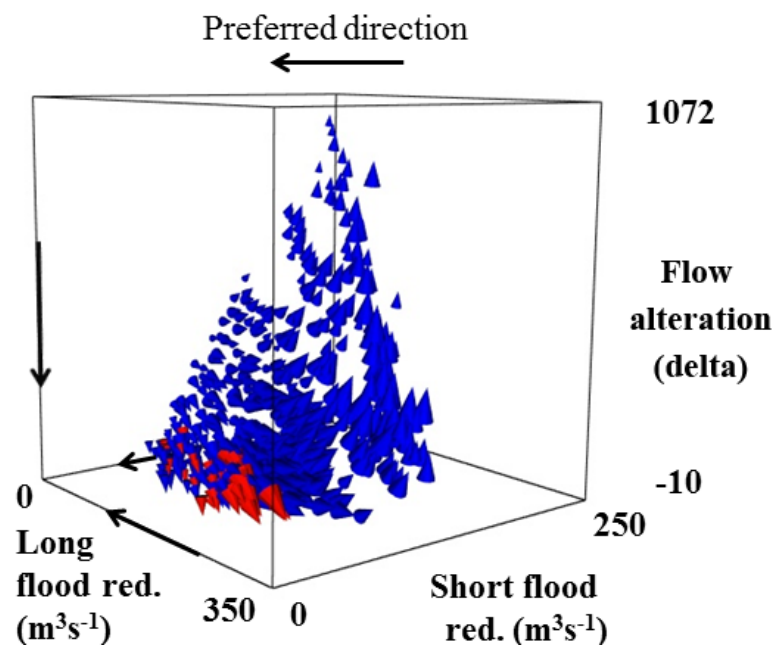

Figure 6. Trade-off surface of the combined current and proposed demands cases (blue cones show system performance when irrigation schemes can be expanded). Some proposed demands solutions dominate the current demands solutions, reducing their representation on the surface. This figure shows how trade-offs achievable by the best system operating rules change once irrigation investments are considered.
The Tana Delta flow regime would be altered by irrigation schemes which withdraw water upstream. The benefit of the proposed approach is that we show the degree of alteration which would occur with the implementation of different scheme sizes. Revenues from the largest irrigated schemes are Pareto-optimal according to the optimisation, but the sacrifice of other benefits to achieve this is high. A limitation of the present work was that irrigation water was assumed to be provided free of charge from source to crop. Had the optimisation included capital and operational costs of supplying irrigation, the trade-offs would have been different. Further non-water-related benefits (e.g. increased local employment) of irrigation schemes could also be included to help assess the significance of the trade-offs involved. An ensemble analysis considering many plausible future flow series may also alter this assessment if water resource availability changes; uncertainty on future flows and demands was not included in this analysis. This paper seeks reservoir operating rules that appropriately meet water manager and/or stakeholder expectations. The rules are designed such that they produce acceptable results over a wide range of hydrological conditions (those present in the historical time series used). The approach could be called implicitly stochastic (Labadie, 2004) since using a long hydrological time series has encapsulated a wide range of hydrological variability. If the hydrological regime were to change in the future, or a series of new assets were put in that would strongly change the system, the study would have to be redone to adapt to new conditions.

Mean hydropower revenue over the modelled period peaks at around USD 100 million year ${ }^{-1}$. This is lower than figures of $\sim$ USD 150 million year ${ }^{-1}$ stated by Kiptala (2008) whose work used flows from a shorter but wetter period from 1966 to 1990 . The hydrological characteristics of this flow time series were inconsistent with the 1934-1975 record used here, preventing their combination. Inconsistencies in 

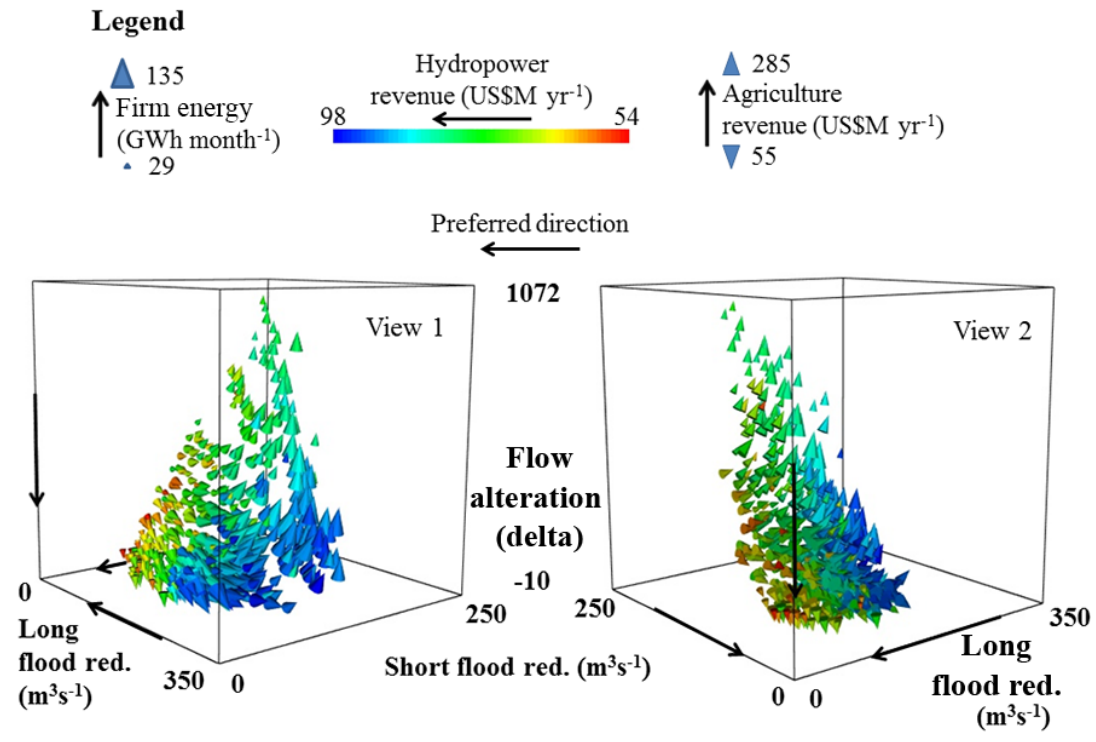

Figure 7. The same trade-off surface as Fig. 5 but with different extents of irrigation scheme implementation. Maximum agricultural revenue more than doubles but maximum flow alteration increases by 5.5 times. Increased agricultural revenue correlates with greater disturbance of the natural water environment. A 3-D animation of this plot is available in online supplementary material.
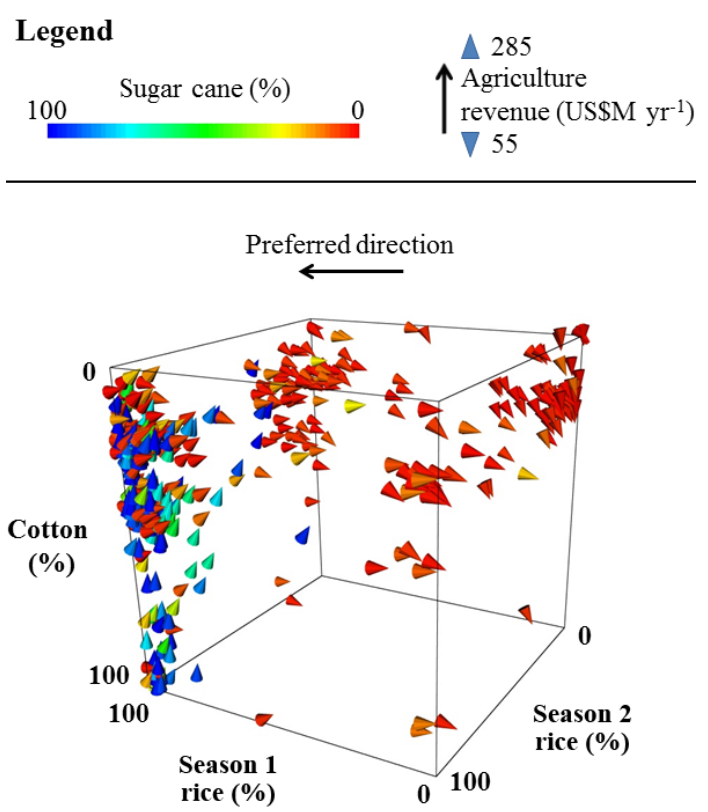

Figure 8. 3-D (non-trade-off) plot showing the relationship between irrigation scheme selection and agricultural revenue. The solution points are the same as those shown in Fig. 7. High revenues can be achieved with or without the implementation of the cotton scheme. A high proportion of all other schemes must be implemented to achieve maximum revenue, however.

data relating to hydraulic head ranges at hydropower turbines may also contribute to the discrepancy in power production/revenue between studies. Further work will attempt to resolve these discrepancies on the basis of more accurate survey data.

A further limitation of this study is the use of proxy objective functions for ecosystem services. Appropriate expertise or further research should be employed to ascertain the significance of different flow regime alterations and to advise on thresholds beyond which individual species, ecosystems or ecosystem services would be severely affected. Local farmers and pastoralists are likely to be better able to describe the relationship between river flows and their livelihoods, allowing more specific and accurate benefit functions to be included in our model. This could replace or enhance our assumptions that entirely natural flow regimes are best providers of ecosystem services.

Opportunities exist to implement further hydropower projects on the river. Further work will seek to define the trade-offs inherent in decisions surrounding two or more new hydropower reservoirs which are proposed for the Tana River. Understanding these trade-offs could help inform both the optimal sizing and combinations of development for balancing system benefits. With infrastructure planning it will also be important to optimise across a range of possible hydrological futures to ensure proposed plans are robust to different plausible future climates.

We suggest that the proposed method can be used for integrated water resources management of systems with a water-energy-food nexus. Revealing trade-offs between stakeholder-defined metrics helps could help orient planners towards solutions that protect livelihoods and the ecosystem services which support them, in addition to obtaining good economic returns. 


\section{Legend}
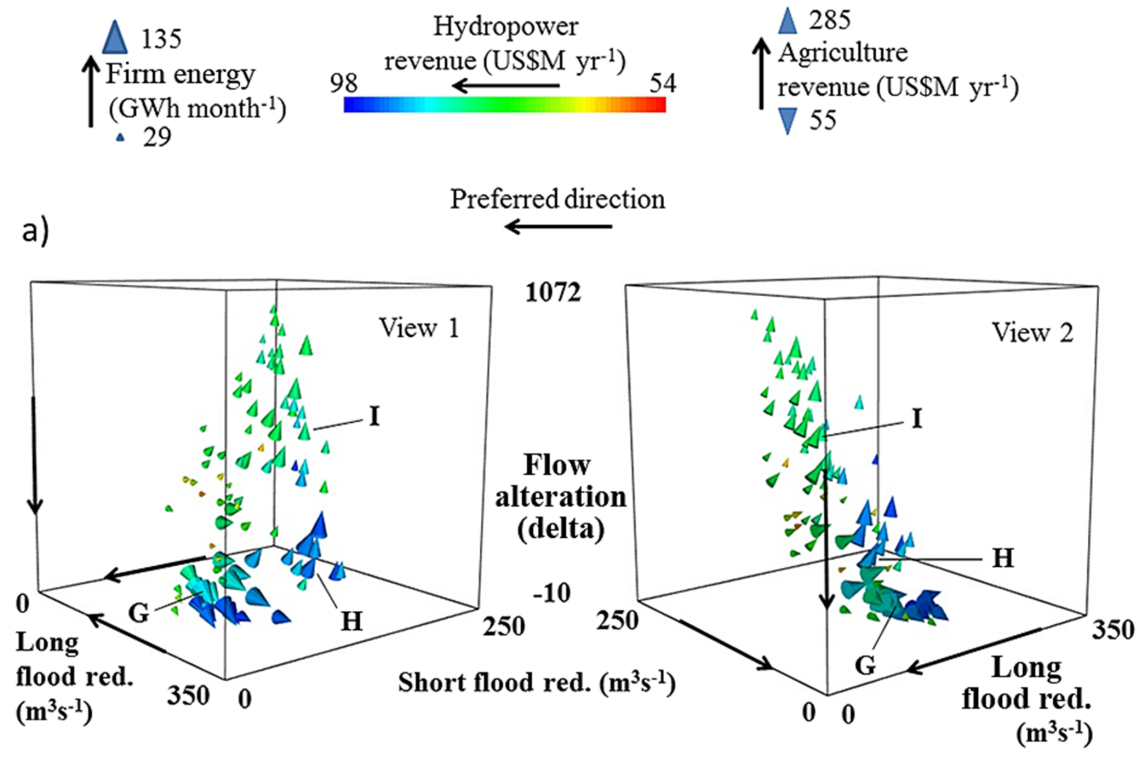

b)

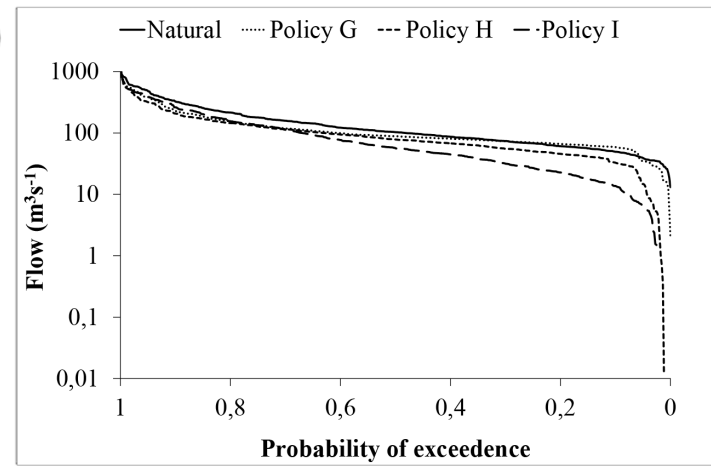

c)

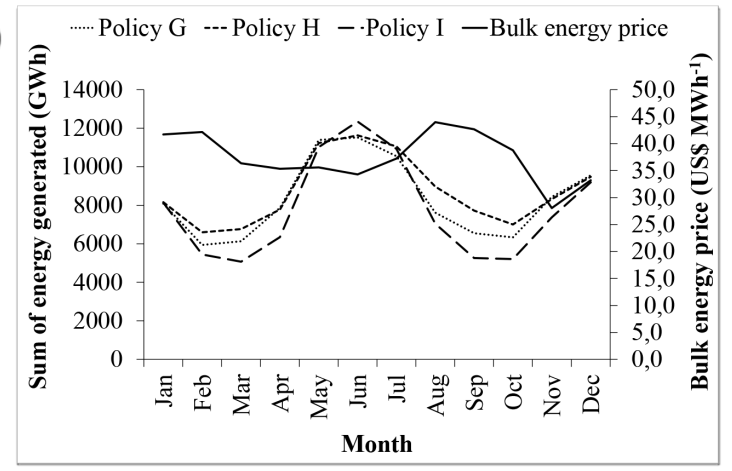

Figure 9. (a) The same trade-off surface as Fig. 7 but restricted to policies which result in no municipal deficits considering historical data. Such "brushing" of trade-off plots allows stakeholders to focus on system designs that interest them. Three policies are selected for discussion. A 3-D animation of this plot is available in online supplementary material. (b) Comparison of the flow duration curves for the three selected operating policies in (a) showing implications of the flow alteration values in Table 1. The Policy G flow regime is closest to natural conditions at both low and mid-range flows, but high flows are sacrificed to increase firm energy. Policies $\mathrm{H}$ and $\mathrm{I}$ result in the river not reaching the ocean for 1-2\% of the time. (c) Plot of the total energy generation for each of three selected policies from (a) alongside the monthly bulk energy price. Higher hydropower revenue (Policy H) is achieved by generating high levels of power in months (August-October) when the bulk energy price is highest. 


\section{Conclusions}

A many-objective visual trade-off analysis of the multireservoir hydropower system on the Kenyan Tana River quantified the relationships between conflicting system objectives achievable under the best system operating rules and irrigation investments. Decision-makers can learn about the consequences of policies or investments by directly viewing their impacts on several objectives and trade-off the various gains and sacrifices according to their preferences. The balance they select is associated with a set of operating rules for the reservoirs which achieve the selected benefits, for a set of hydrological conditions (in our case the historical record). For the proposed demands case, each Pareto-optimal solution in the trade-off plots also corresponds to a specific set of new irrigation schemes in the Tana Delta.
Eight objectives were considered in this many-objective study, representing benefits to municipalities, a national primate reserve, pastoralists seeking grazing in a protected wetland, riparian farming tribes, the hydropower company and irrigated agriculture. Considering these objectives, full implementation of the proposed irrigation schemes is Paretooptimal, but would involve large sacrifices of non-market benefits. This finding concurs with other work on the Tana Basin, suggesting that the implementation of large irrigation schemes would impact heavily on the delta's ecosystem services (Duvail et al., 2012). The visual trade-off analysis used here helps improve understanding and communication of the incremental impacts management and investment decisions would have. This approach is appropriate for linked water, energy and food systems where management and planning decisions imply a complex distribution of benefits between actors and sectors competing for resources. The approach simultaneously identifies a wide range of decisions which cannot be improved upon without decreasing some benefit, and visualises the outcomes for different stakeholders. Because the approach links integrated simulation models to a separate search algorithm, there is potential to use this approach with a wide range of system simulators. Future work will follow and develop the proposed approach with stakeholders and decision-makers to assess its usefulness in assisting them to identify the best system plans, assess their impacts, deliberate the trade-offs implied, and reach consensual decisions in a transparent manner. 
Table A1. Non-hydropower demands by month on reservoirs in the Seven Forks project (in $\mathrm{m}^{3} \mathrm{~s}^{-1}$ ) (Kiptala, 2008) applied to both cases.

\begin{tabular}{lrrrr}
\hline & \multicolumn{4}{c}{ Reservoir } \\
\cline { 2 - 5 } & Masinga & \multicolumn{3}{c}{$\begin{array}{r}\text { Municipal } \\
\text { (Nairobi \& } \\
\text { Kitui) }\end{array}$} \\
\hline Month & Rice & Horticulture & Maize \\
\hline Jan & 17.6 & 1.3 & 2.2 & 3.9 \\
Feb & 18.9 & 0.0 & 2.2 & 1.4 \\
Mar & 19.7 & 0.7 & 2.2 & 0.0 \\
Apr & 0.0 & 2.3 & 2.2 & 0.0 \\
May & 0.0 & 5.0 & 2.2 & 2.5 \\
Jun & 0.0 & 5.3 & 2.2 & 4.8 \\
Jul & 13.8 & 1.6 & 2.2 & 4.3 \\
Aug & 13.4 & 0.0 & 2.2 & 1.3 \\
Sep & 19.5 & 1.6 & 2.2 & 0.0 \\
Oct & 18.7 & 3.1 & 2.2 & 0.7 \\
Nov & 0.0 & 4.3 & 2.2 & 1.7 \\
Dec & 16.7 & 3.5 & 2.2 & 3.2 \\
\hline
\end{tabular}

Table A2. Monthly demands for proposed irrigation crops in the Tana Delta (in $\mathrm{m}^{3} \mathrm{~s}^{-1}$ ) (Kiptala, 2008) applied only in the proposed demands case according to the proportions determined by related decision variables.

\begin{tabular}{lrrrr}
\hline \multicolumn{5}{c}{ Crop } \\
\hline Month & $\begin{array}{r}\text { Rice } \\
\text { Season 1 }\end{array}$ & $\begin{array}{r}\text { Rice } \\
\text { Season 2 }\end{array}$ & Cotton & Sugarcane \\
\hline Jan & 20.2 & 0.0 & 3.3 & 112.0 \\
Feb & 21.8 & 0.0 & 0.0 & 83.5 \\
Mar & 22.7 & 0.0 & 0.0 & 29.9 \\
Apr & 0.0 & 0.0 & 0.0 & 44.8 \\
May & 0.0 & 0.0 & 0.0 & 121.7 \\
Jun & 0.0 & 0.0 & 0.0 & 159.7 \\
Jul & 0.0 & 16.0 & 3.6 & 156.8 \\
Aug & 0.0 & 15.5 & 6.3 & 160.5 \\
Sep & 0.0 & 22.5 & 10.5 & 167.4 \\
Oct & 0.0 & 21.5 & 8.9 & 143.4 \\
Nov & 0.0 & 0.0 & 8.4 & 116.5 \\
Dec & 19.3 & 0.0 & 8.3 & 99.3 \\
\hline
\end{tabular}

\section{Appendix A: Demand data}

This appendix gives demand data relating to the two optimisation cases. Table A1 includes demands applied to both cases. Table A2 gives maximum demands for the four proposed irrigation schemes in the delta.

\section{Appendix B: Objective function details}

This appendix presents the mathematical formulation of objective functions used for optimisation. Table A1 details the objectives as they relate to the optimisation before mathematical formulations are presented for each.

\section{B1 Municipal deficit}

Minimise $f_{\text {mun }}=\frac{1}{Y} \sum_{y=1}^{Y}\left(\sum_{i} \operatorname{Deficit}_{y}^{i}\right)$

$i \in\{$ Nairobi, Kitui, Downstream $\}$,

where $y$ is the year in the time horizon, $Y$ is the total number of simulated years, $i$ is a municipal demand and Deficit $t_{y}^{i}$ represents deficit experienced by municipal demand $i$ during year $y$.

\section{B2 Hydropower revenue}

Maximise $f_{\text {hydro }}=\frac{1}{Y} \sum_{y=1}^{Y}\left(\sum_{i} \operatorname{Revenue}_{y}^{i}\right)$

$i \in\{$ Masinga, Kiamburu, Gitaru, Kindaruma, Kiambere $\}$, where $y$ is the year in the time horizon, $Y$ is the total number of simulated years and Revenue ${ }_{y}^{i}$ is the revenue generated by the hydropower plant at reservoir/pondage $i$ in year $y$.

\section{B3 Firm energy}

Maximise $f_{\text {firm }}=$ LowGen,

where LowGen is the 10th percentile value of monthly total energy generation during the 42 year simulation.

\section{B4 Agricultural revenue}

Maximize $f_{\text {agric }}=\frac{1}{Y} \sum_{y=1}^{Y}\left(\sum_{i} \operatorname{AgRevenue}_{y}^{i}\right)$

$i \in\{$ Masinga, Kiambere, Delta $\}$,

where AgRevenue $e_{y}^{i}$ is the agricultural revenue associated with irrigation demands in supply region $i$ in year $y$.

\section{B5 Flow alteration}

Two flow alteration objectives are evaluated, but as these share a common formulation, a generic form is presented here to avoid duplication.

Minimize $f_{\text {flow }}=-\sum_{d}\left(1-\frac{\sum_{t=1}^{\mathrm{TD}}\left(\mathrm{FFC}_{t}^{\mathrm{u}}-\mathrm{FFC}_{t}^{\mathrm{r}}\right)^{2}}{\sum_{t=1}^{\mathrm{TD}}\left(\mathrm{FFC}_{t}^{\mathrm{u}}-\mathrm{FF} C_{d}^{\mathrm{u}}\right)^{2}}\right)_{d}$

$d=\{1,2,3,4,5,6,7,8,9,10\}$,

where $d$ is a decile of the flow duration curve at the objective evaluation site, $t$ is a time step, TD is the total number of time steps within decile $d$, FFC $t_{t}^{\mathrm{u}}$ represents the unregulated 
Table B1. Objective function goals, results precision, units and comments.

\begin{tabular}{|c|c|c|c|c|}
\hline Objective & Function & Goal & $\begin{array}{l}\text { Results } \\
\text { precision } \\
\& \text { units }\end{array}$ & Comments \\
\hline $\begin{array}{l}\text { Municipal } \\
\text { deficit }\end{array}$ & $f_{\text {mun }}$ & Minimise & $0.25 \mathrm{Mm}^{3}$ year $^{-1}$ & $\begin{array}{l}\text { Evaluated as the sum of deficits during the simulation, divided } \\
\text { by the number of years to give a mean annual value. }\end{array}$ \\
\hline $\begin{array}{l}\text { Hydropower } \\
\text { revenue }\end{array}$ & $f_{\text {hydro }}$ & Maximise & USD $_{1}$ million year ${ }^{-1}$ & $\begin{array}{l}\text { Total revenue from the five stations according to the } 2007 \text { bulk } \\
\text { energy prices from Kiptala ( } 2008 \text { ), divided by the years sim- } \\
\text { ulated to give mean annual revenue. }\end{array}$ \\
\hline Firm energy & $f_{\text {firm }}$ & Maximise & $1 \mathrm{GWh}$ month $^{-1}$ & \\
\hline $\begin{array}{l}\text { Total } \\
\text { agricultural } \\
\text { revenue }\end{array}$ & $f_{\text {agric }}^{\text {total }}$ & Maximise & USD $_{1}$ million year ${ }^{-1}$ & $\begin{array}{l}\text { Crop yield responses to water deficit (Doorenbos and Kas- } \\
\text { sam, 1979) used to calculate yields. Yields converted to rev- } \\
\text { enues using commodity prices in Kiptala (2008). Objective } \\
\text { evaluates whole system for both cases. }\end{array}$ \\
\hline $\begin{array}{l}\text { Delta flow } \\
\text { alteration }\end{array}$ & $f_{\text {flowDEL }}$ & Minimise & $10-$ & $\begin{array}{l}\text { Evaluated as negative sum of Nash-Sutcliffe efficiencies } \\
\text { (Nash and Sutcliffe, 1970) for } 10 \text { corresponding deciles of }\end{array}$ \\
\hline $\begin{array}{l}\text { Forest flow } \\
\text { alteration }\end{array}$ & $f_{\text {flowFOR }}$ & Minimise & $10-$ & $\begin{array}{l}\text { natural and regulated flow duration curves. Negative sum is } \\
\text { used to make objective more intuitive }- \text { i.e. ecosystem bene- } \\
\text { fits are preserved by minimising, rather than maximising flow } \\
\text { regime alteration. Theoretical range of objective is }-10 \text { to } \infty \text {, } \\
\text { although physical limits mean value unlikely to approach } \infty \text {. }\end{array}$ \\
\hline $\begin{array}{l}\text { Long } \\
\text { flood peak } \\
\text { reduction } \\
\text { Short } \\
\text { flood peak } \\
\text { reduction }\end{array}$ & $f_{\text {flood }}^{\text {long }}$ & Minimise & $10 \mathrm{~m}^{3} \mathrm{~s}^{-1}$ & $\begin{array}{l}\text { Flooding results from controlled releases through dam gates } \\
\text { and uncontrolled releases over the dam spillways. Objectives } \\
\text { are controlled by the operation of the downstream dam, Ki- } \\
\text { ambere, although upstream dam operations affect water avail- } \\
\text { able at Kiambere. Evaluated as an absolute sum of differences } \\
\text { between flows for the whole simulation. }\end{array}$ \\
\hline
\end{tabular}

flow frequency curve value for time step $t, \mathrm{FFC}_{t}^{\mathrm{r}}$ represents the regulated flow frequency curve value for time step $t$ and $\overline{\mathrm{FFC}}{ }_{d}^{\mathrm{u}}$ is the mean value of unregulated flow frequency curve in $d$.

\section{B6 Long flood peak reduction}

Maximize $f_{\text {flood }}^{\text {long }}=\sum_{y=1}^{Y}\left(\sum_{i} \mid \operatorname{NatFlow~}_{y}^{i}-\right.$ ModFlow $\left._{y}{ }_{y} \mid\right)$

$i \in\{$ April, May, June $\}$,

where NatFlow $_{y}^{i}$ is the natural (observed) flow rate and ModFlow $_{y}^{i}$ is the modified (modelled) flow rate for month $i$ in year $y$.

\section{B7 Short flood peak reduction}

$\operatorname{Maximize} f_{\text {flood }}^{\text {short }}=\sum_{y=1}^{Y}\left(\sum_{i} \mid \operatorname{NatFlow~}_{y}^{i}-\right.$ ModFlow $\left._{y}^{i} \mid\right)$

$i \in\{$ October, November, December $\}$,
Table C1. Yield response factors for crops proposed for delta irrigation schemes (based on Doorenbos and Kassam, 1979).

\begin{tabular}{lr}
\hline Crop & $\begin{array}{r}\text { Yield } \\
\text { response factor }\end{array}$ \\
\hline Rice & 1.0 \\
Maize & 1.25 \\
Cotton & 0.85 \\
Sugarcane & 1.2 \\
\hline
\end{tabular}

where $\mathrm{NatFlow}_{y}^{i}$ is the natural (observed) flow rate and ModFlow $_{y}^{i}$ is the modified (modelled) flow rate for month $i$ in year $y$.

\section{Appendix C: Formulation and parameterisation of the crop yield module added to IRAS-2010}

This appendix gives details of the crop yield calculation module added to IRAS-2010 in order to evaluate agricultural revenue. The module added is based on work by Doorenbos and Kassam (1979) on crop yield response to water. 
Doorenbos and Kassam (1979) developed an equation (C1) relating crop yields to maximum possible yields, actual and maximum evapotranspiration. In order to simplify the calculation we used the ratio of irrigation supplied to irrigation demand as a proxy for the ratio of actual to potential evapotranspiration. We justify this by the statement in Doorenbos and Kassam (1979) that available water supply to the crop controls actual evapotranspiration. It was necessary to assume that the only water received by crops in this region is irrigation. This is reasonable under the semi-arid climate.

$$
\left(1-\frac{Y_{\mathrm{a}}}{Y_{\mathrm{x}}}\right)=K_{\mathrm{y}}\left(1-\frac{\mathrm{ET}_{\mathrm{a}}}{\mathrm{ET}_{\mathrm{x}}}\right)
$$

where $Y_{\mathrm{x}}$ and $Y_{\mathrm{a}}$ are the maximum and actual yields, $\mathrm{ET}_{\mathrm{x}}$ and $\mathrm{ET}_{\mathrm{a}}$ are the maximum and actual evapotranspiration, and $K_{\mathrm{y}}$ is a yield response factor representing the effect of a reduction in evapotranspiration on yield losses.
Yield response factors used to calculate yields in the IRAS-2010 module are shown in Table C1. No response factor for rice was given by Doorenbos and Kassam (1979) so it was assumed that yield was directly proportional to water deficit. This was simpler than trying to judge a factor without evidence to support its value. 
Acknowledgements. Discussions with Mark Smith and James Dalton (IUCN), Matthew McCartney (IWMI), Eric Odada (Univ. Nairobi) and Peter Newborne (ODI), provided encouragement to initiate this research. Future work will be part of the WISE-UP to Climate project led by IUCN and funded by the International Climate Initiative (IKI) of the German Federal Ministry for the Environment, Nature Conservation and Nuclear Safety (BMU). We are grateful for information about the Tana system from Amaury Tilmant and Jeremiah Kiptala (UNESCO-IHE) and data and advice from Atieno Omuombo (Univ. Nairobi). Ivana Huskova, Joe Kasprzyk and Patrick Reed provided valuable assistance in the optimisation work. We acknowledge the use of the UCL Legion High Performance Computing Facility and data from The Global Runoff Data Centre, 56068 Koblenz, Germany. The authors bear responsibility for any errors.

Edited by: Y. Cai

\section{References}

Abson, D. J. and Termansen, M.: Valuing Ecosystem Services in Terms of Ecological Risks and Returns, Conserv. Biol., 25, 250 258, doi:10.1111/j.1523-1739.2010.01623.x, 2011.

Birol, E., Karousakis, K., and Koundouri, P.: Using economic valuation techniques to inform water resources management: A survey and critical appraisal of available techniques and an application, Sci. Total Environ., 365, 105-122, doi:10.1016/j.scitotenv.2006.02.032, 2006.

Chakravarty, S.: Cost-benefit analysis, Palgrave Macmillan, Basingstoke, UK, 1987.

Coello, C. A. C., Lamont, G. B., and Van Veldhuisen, D. A.: Evolutionary Algorithms for Solving Multi-objective Problems, Springer Science + Business Media, LLC, 2007.

Cohon, J. L.: Multiobjective programming and planning Jared L. Cohon, xiv, 333, 1978.

Connell, J. H.: Intermediate-disturbance hypothesis, Science, 204, 1345-1345, doi:10.1126/science.204.4399.1345, 1979.

Dagg, M., Woodhead, T., and Rijks, D. A.: Evaporation in east africa, International Association of Scientific Hydrology, Bulletin, 15, 61-67, 1970

Davies, J.: Total Economic Valuation of Kenyan Pastoralism, IUCN, available at: http://cmsdata.iucn.org/downloads/kenya_ tev.pdf, 2007.

Doorenbos, J. and Kassam, A. H.: Yield response to water, Irrigation and Drainage Paper 33, Food and Agriculture Organization of the United Nations, Rome, 193 pp., 1979.

Duvail, S., Médard, C., Hamerlynck, O., and Nyingi, D. W.: Land and water grabbing in an East African coastal wetland: The case of the Tana delta, Water Alternativ., 5, 322-343, 2012.

Emerton, L.: Values and Rewards: Counting and Capturing Ecosystem Water Services for Sustainable Development, IUCN Water, Nature and Economics Technical Paper No. 1, IUCN - The World Conservation Union, 2005.

Fleming, P. J., Purshouse, R. C., and Lygoe, R. J.: Many-objective optimization: An engineering design perspective, Evolut. MultiCriterion Optim., 3410, 14-32, 2005.
Gao, Y. X., Vogel, R. M., Kroll, C. N., Poff, N. L., and Olden, J. D.: Development of representative indicators of hydrologic alteration, J. Hydrol., 374, 136-147, doi:10.1016/j.jhydrol.2009.06.009, 2009.

Godfray, H. C. J., Beddington, J. R., Crute, I. R., Haddad, L., Lawrence, D., Muir, J. F., Pretty, J., Robinson, S., Thomas, S. M., and Toulmin, C.: Food Security: The Challenge of Feeding 9 Billion People, Science, 327, 812-818, doi:10.1126/science.1185383, 2010.

Granit, J., Jagerskog, A., Lindstrom, A., Bjorklund, G., Bullock, A., Lofgren, R., de Gooijer, G., and Pettigrew, S.: Regional Options for Addressing the Water, Energy and Food Nexus in Central Asia and the Aral Sea Basin, Int. J. Water Resour. Develop., 28, 419-432, doi:10.1080/07900627.2012.684307, 2012.

Grey, D. and Sadoff, C. W.: Sink or Swim? Water security for growth and development, Water Pol., 9, 545-571, doi:10.2166/wp.2007.021, 2007.

GWP: Integrated Water Resources Management, TAC Background Papers, edited by: Committee, T. A., Global Water Partnership, Stockholm, Sweden, 2000.

GWP: Poverty Reduction and IWRM, Global Water Partnership, Sweden 91-974559-0-3, 2003.

Harou, J. J., Pulido-Velazquez, M. A., Rosenberg, D. E., MedellinAzuara, J., Lund, J. R., and Howitt, R.: Hydro-economic Models: Concepts, Design, Applications and Future Prospects, J. Hydrol., 375, 334-350, 2009.

Hughes, F. M. R.: The influence of flooding regimes on forest distribution and composition in the tana river floodplain, Kenya, J. Appl. Ecol., 27, 475-491, doi:10.2307/2404295, 1990.

Hurford, A. P., Huskova, I., and Harou, J. J.: Using many-objective trade-off analysis to help dams promote economic development, protect the poor and enhance ecological health, Environ. Sci. Pol., 38, 72-86, doi:10.1016/j.envsci.2013.10.003, 2014.

Juana, J. S., Mangadi, K. T., and Strzepek, K. M.: The socio-economic impacts of climate change on water resources in South Africa, Water Int., 37, 265-278, doi:10.1080/02508060.2012.687505, 2012.

Karere, G. M., Oguge, N. O., Kirathe, J., Muoria, P. K., Moinde, N. N., and Suleman, M. A.: Population sizes and distribution of primates in the lower Tana River forests, Kenya, Int. J. Primatol. 25, 351-365, doi:10.1023/b:ijop.0000019156.41782.53, 2004.

Kasprzyk, J. R., Reed, P. M., Kirsch, B. R., and Characklis, G. W. Managing population and drought risks using many-objective water portfolio planning under uncertainty, Water Resour. Res., 45, W12401, doi:10.1029/2009wr008121, 2009.

Keim, D., Andrienko, G., Fekete, J. D., Gorg, C., Kohlhammer, J., and Melancon, G.: Visual analytics: Definition, process, and challenges, in: Information Visualization: Human-Centered Issues and Perspectives, edited by: Kerren, A., Stasko, J. T., Fekete, J. D., and North, C., Lecture Notes in Computer Science, 154 $175,2008$.

Kinnaird, M. F.: Phenology of flowering and fruiting of an EastAfrican riverine forest ecosystem, Biotropica, 24, 187-194, doi:10.2307/2388672, 1992.

Kiptala, J. K.: Intersectoral Allocation in the Tana River Basin (Kenya), Master of Science, Institute for Water Education, UNESCO-IHE, Delft, 2008. 
Kollat, J. B. and Reed, P. M.: Comparing state-of-the-art evolutionary multi-objective algorithms for long-term groundwater monitoring design, Adv. Water Resour., 29, 792-807, doi:10.1016/j.advwatres.2005.07.010, 2006.

Kollat, J. B. and Reed, P.: A framework for visually interactive decision-making and design using evolutionary multi-objective optimization (VI(D)under-barEO), Environ. Modell. Softw., 22, 1691-1704, doi:10.1016/j.envsoft.2007.02.001, 2007.

Kollat, J. B., Reed, P. M., and Kasprzyk, J. R.: A new epsilon-dominance hierarchical Bayesian optimization algorithm for large multiobjective monitoring network design problems, Adv. Water Resour., 31, 828-845, doi:10.1016/j.advwatres.2008.01.017, 2008.

Kollat, J. B., Reed, P. M., and Maxwell, R. M.: Manyobjective groundwater monitoring network design using biasaware ensemble Kalman filtering, evolutionary optimization, and visual analytics, Water Resour. Res., 47, W02529, doi:10.1029/2010wr009194, 2011.

Konrad, C. P., Warner, A., and Higgins, J. V.: Evaluating dam reoperation for freshwater conservation in the sustainable rivers project, River Res. Appl., 28, 777-792, doi:10.1002/rra.1524, 2012.

Labadie, J. W.: Optimal Operation of Multireservoir Systems: Stateof-the-Art Review, J. Water Resour. Plann. Manage., 130, 93111, doi:10.1061/(ASCE)0733-9496(2004)130:2(93), 2004.

Leauthaud, C., Duvail, S., Hamerlynck, O., Paul, J.-L., Cochet, H., Nyunja, J., Albergel, J., and Gruenberger, O.: Floods and livelihoods: The impact of changing water resources on wetland agroecological production systems in the Tana River Delta, Kenya, Global Environ. Change-Human Pol. Dimensions, 23, 252-263, doi:10.1016/j.gloenvcha.2012.09.003, 2013.

Lotov, A. V.: Visualization of pareto frontier in environmental decision making, Environ. Secur. Harbor. Coastal Areas: Management Using Comparative Risk Assessment and MultiCriteria Decision Analysis, 275-292, doi:10.1007/978-1-40205802-8_19, 2007.

Loucks, D. P., Van Beek, E., Stedinger, J. R., Dijkman, J. P. M., and Villars, M. T.: Water Resources Systems Planning and Management: An Introduction to Methods, Models and Applications, Unesco, 2005.

Maass, A., Hufschmidt, M. M., Dorfman, R., Thomas, H. A., Jr., Marglin, S. A., and Fair, G. M.: Design of water-resource systems, Harvard University Press, Cambridge, Mass., 1962.

Maingi, J. K. and Marsh, S. E.: Quantifying hydrologic impacts following dam construction along the Tana River, Kenya, J. Arid Environ., 50, 53-79, doi:10.1006/jare.2000.0860, 2002.

Malley, Z. J. U., Taeb, M., Matsumoto, T., and Takeya, H.: Environmental change and vulnerability in the Usangu plain, southwestern Tanzania: Implications for sustainable development, Int. J. Sustain. Develop. World Ecol., 14, 145-159, 2007.

Matrosov, E. S., Harou, J. J., and Loucks, D. P.: A computationally efficient open-source water resource system simulator - Application to London and the Thames Basin, Environ. Modell. Softw., 26, 1599-1610, doi:10.1016/j.envsoft.2011.07.013, 2011.

McCully, P.: Silenced Rivers: The Ecology and Politics of Large Dams, Zed Books Ltd, London, 2001.
Merrey, D. J., Drechsel, P., de Vries, F. W. T. P., and Sally, H.: Integrating "livelihoods" into integrated water resources management: taking the integration paradigm to its logical next step for developing countries, Reg. Environ. Change, 5, 197-204, doi:10.1007/s10113-004-0088-5, 2005.

Mitsch, W. J. and Gosselink, J.: Wetlands, Wiley, New York, 2000.

Mireri, C., Onjla, J., and Oguge, N.: The Economic Valuation of the Proposed Tana Integrated Sugar Project (TISP), Kenya, Nature Kenya, Kenya, 2008.

Nash, J. E. and Sutcliffe, J. V.: River flow forecasting through conceptual models part I - A discussion of principles, J. Hydrol., 10, 282-290, doi:10.1016/0022-1694(70)90255-6, 1970.

Paton, J. and Bryant, G.: Valuing Pollution: Problems of Price in the Commodification of Nature, Econom. Labour Relations Rev., 23, 87-106, 2012.

Ramsar: Tana River Delta added to the Ramsar List: available at: http://www.ramsar.org/cda/en/ ramsar-news-archives-2012-kenya-tana/main/ramsar/ 1-26-45-520\%5E25948_4000_0 (last access: 9 July), 2012.

Reed, P. M., Hadka, D., Herman, J. D., Kasprzyk, J. R., and Kollat, J. B.: Evolutionary multiobjective optimization in water resources: The past, present, and future, Adv. Water Resour., 51, 438-456, doi:10.1016/j.advwatres.2012.01.005, 2013.

Renofalt, B. M., Jansson, R., and Nilsson, C.: Effects of hydropower generation and opportunities for environmental flow management in Swedish riverine ecosystems, Freshw. Biol., 55, 49-67, doi:10.1111/j.1365-2427.2009.02241.x, 2010.

Richter, B. D. and Thomas, G. A.: Restoring environmental flows by modifying dam operations, Ecol. Soc., 12, available at: http: //www.ecologyandsociety.org/vol12/iss1/art12/, 2007.

Richter, B. D., Baumgartner, J. V., Powell, J., and Braun, D. P.: A method for assessing hydrologic alteration within ecosystems, Conserv. Biol., 10, 1163-1174, doi:10.1046/j.15231739.1996.10041163.x, 1996.

Sagoff, M.: Environmental economics and the conflation of value and benefit, Environ. Sci. Technol., 34, 1426-1432, doi:10.1021/es990674d, 2000.

Sagoff, M.: On the economic value of ecosystem services, Environ. Values, 17, 239-257, doi:10.3197/096327108x303873, 2008.

Sagoff, M.: The quantification and valuation of ecosystem services, Ecol. Econom., 70, 497-502, doi:10.1016/j.ecolecon.2010.10.006, 2011.

Shih, J.-S. and ReVelle, C.: Water-Supply Operations during Drought: Continuous Hedging Rule, J. Water Resour. Plann. Manage., 120, 613-629, 1994.

Shukla, P. K., Deb, K., and Tiwari, S.: Comparing classical generating methods with an evolutionary multi-objective optimization method, Evolut. Multi-Criterion Optimiz., 3410, 311-325, 2005.

Steele, S. R.: Expanding the solution set: Organizational economics and agri-environmental policy, Ecol. Econom., 69, 398-405, doi:10.1016/j.ecolecon.2009.08.014, 2009.

Watts, R. J., Ryder, D. S., Allan, C., and Commens, S.: Using riverscale experiments to inform variable releases from large dams: a case study of emergent adaptive management, Mar. Freshw. Res., 61, 786-797, doi:10.1071/mf09190, 2010.

WCD: Dams and Development: A New Framework for DecisionMaking: Report of the World Commission on Dams, Earthscan Publications, London, 2000. 
Wilson, M. A. and Carpenter, S. R.: Economic valuation of freshwater ecosystem services in the United States: 1971-1997, Ecol. Applic., 9, 772-783, doi:10.2307/2641328, 1999.

Winpenny, J.: Managing Water as an Economic Resource, Taylor \& Francis, 1993.
Yeh, W. W. G.: Reservoir management and operations models a state-of-the-art review, Water Resour. Res., 21, 1797-1818, doi:10.1029/WR021i012p01797, 1985.

Yergin, D.: Ensuring energy security, Foreign Affairs, 85, 69-82, doi:10.2307/20031912, 2006. 